\title{
Simulation of the Explosion of Kerosene Vapors Inside a Partitioned Structure
}

\author{
C. Strozzi, P. Gillard and J.M. Pascaud \\ Laboratoire Prisme - Université d'Orléans \\ 63, avenue de Lattre de Tassigny \\ 18020 BOURGES Cedex, France
}

Corresponding author: camille.strozzi@ bourges.univ-orleans.fr

\begin{abstract}
The aim of this work is to propose a simple multi-physics model in order to predict the evolution of the thermodynamic variables during the combustion of kerosene vapors in each compartment of a closed vessel. A special attention is paid to the mechanical effects of combustion, e.g. the pressure evolution. The basic characteristics of the model have been developed as part of a Computational Fluid Dynamics (CFD) approach, in order to represent both the ignition stage and the flame propagation in the reactive mixture. The proposed development is validated in a single compartment vessel by investigations about the equivalence ratio and the reaction dynamics (final pressure, combustion duration, etc.). Moreover, the expected phenomenology is correctly reproduced for tanks composed of several compartments, such as for instance, a faster combustion process in presence of internal orifices. The impact of the ignition on the subsequent evolution of the explosion is also investigated, highlighting a strong influence of the ignition location. The model illustrates that the pressure evolution is the result of complex geometry effects: particularly, for a tank made of identical compartments, the total volume is not sufficient to describe the main trends concerning the mechanical effects of the explosion. The calculations are in agreement with classical results available in the literature for a special kind of kerosene (F.34) studied by the laboratory. Despite the proposed model relies on simple assumptions, it represents a useful tool for further vulnerability or risk assessment studies applied to aircraft kerosene tanks.
\end{abstract}

Keywords: Explosion, kerosene vapors, aircraft tank.

\section{Introduction}

Over the last past years, there has been a considerable effort to specify the characteristics of the combustion of heavy fuels [1,2]. The combustion of kerosene has received much recent attention $[3,4]$ because of its importance in power-generating equipment, especially in high output military aircraft propulsion systems. Various models have been developed to calculate the burning velocity or determine the reaction temperatures. The aim of such studies is to make easier conceiving and manufacturing of systems used in aeronautics and also to study their behaviour and the influence of various parameters by reducing the length and the costs of laboratory tests. The physical processes involved in ignition and combustion of fuels like kerosene are generally complex. Classical models take into account thermal and radiative transfers, the heat of combustion and a complete development of the chemical kinetics with numerous reactions [5]. The corresponding calculation codes are generally heavy and their predictions often remain limited for partitioned vessels.

The aim of this work is to present a simple multi-physics simulation able to describe the combustion of kerosene vapors in a closed vessel with applications to complex partitioned structures. The model we have developed may be easily implemented in an industrial environment. Previous works have been performed about the combustion of liquid fuel droplets [6]. A different calculation methodology is presently reported allowing the determination of the thermodynamic 
variables by the resolution of a system of partial differential equations taking into account heat and mass transport phenomena and the flow in the vessel. Equations are solved for the mass continuity, the momentum, the temperature and the fuel concentration. They rely on laminar and weakly compressible flow assumptions for an ideal gas. These simple but clearly stated hypotheses are retained in order to provide with a single model a description of both the ignition induced by a heat flux and the subsequent flame propagation, which is a challenging task. The physical phenomena encountered in the framework of aircraft tank vulnerability studies are numerous and complex. They are therefore difficult to handle with a single model. For example, the effects of turbulence are not explicitely taken into account, as part of a first step in the model development. These intrinsic limitations should be considered for quantitative studies over large ranges of experimental conditions. Moreover, the absence of detonation waves in the reactive mixture is assumed, because ignition energies considered herein (up to $150 \mathrm{~J}$ ) are much lower than the critical energy necessary for initiating spherical detonations near the stoichiometry for a kerosene-air mixture $(\sim 150 \mathrm{~kJ})$, see [7]. The occurrence of a deflagration to detonation transition is not expected either for the tank geometries considered here, see [7]. Despite its simplicity, the present manuscript shows that the proposed approach is useful for further practical studies related to risk estimation or vulnerability.

The calculation code is based on a CFD approach within a single tank and then in a partitioned geometry using Comsol 3.4 finite element solver. The model allows the study of the pressure or the temperature distributions in the vessel, the pressure or the temperature histories and the profiles of various parameters projected on a given geometry. The relevance of the model is showed in the case of varied conditions such as the influence of the equivalence ratio (rich or lean mixture), the influence of thermodynamic initial conditions (pressure $P_{o}$, temperature $T_{0}$, volume $V_{o}$ ) and the influence of the supply, the size and the location of the ignition energy in a partitioned vessel. This work has been developed in order to improve safety in Aeronautics and may be useful for the understanding of explosions in impacted aircraft tanks.

\section{Model description}

The combustion of a special kind of kerosene (F.34) is essentially described in its gaseous phase. In a first time, a global one-step chemical reaction has been envisaged for the decomposition of a kerosene $\mathrm{C}_{\mathrm{x}} \mathrm{H}_{\mathrm{y}}$ such as $[8,9]$ :

$$
\begin{aligned}
\mathrm{C}_{\mathrm{x}} \mathrm{H}_{\mathrm{y}}+\mathrm{mO}_{2} \rightarrow & \alpha \mathrm{CO}_{2}+(\mathrm{x}-\alpha-\beta) \mathrm{CO}+(2 \mathrm{~m}-2 \mathrm{r}-\mathrm{x}-\alpha+\beta) \mathrm{H}_{2} \mathrm{O} \\
& +\left(\frac{\mathrm{y}}{2}+\mathrm{x}+\alpha-\beta+2 \mathrm{r}-2 \mathrm{~m}\right) \mathrm{H}_{2}+\mathrm{rO}_{2}+\beta \mathrm{C}^{\mathrm{s}}
\end{aligned}
$$

The liquid fuel is introduced into the tank containing air at the initial temperature $\mathrm{T}_{\mathrm{o}}$. Some molecules change from the liquid phase to the gaseous phase. The equilibrium between both liquid and gaseous phases is obtained when the partial pressure of the fuel vapor reaches the saturated vapor pressure. The combustion of the kerosene vapors is linked to the combustion of molecules perfectly stirred. The equivalence ratio of the mixture is completely determined by the thermodynamic conditions in the vessel and therefore by the characteristics of the gaseous phase. Using Dalton's law on the partial pressures the equivalence ratio $\varphi$ of the mixture is then [9]:

$$
\varphi=\frac{\mathrm{m}_{\text {sto }}}{\mathrm{m}}=\mathrm{m}_{\text {sto }} \frac{\mathrm{P}_{\text {ker }}}{\mathrm{P}_{\mathrm{o}}-\mathrm{P}_{\text {ker }}}
$$

$\mathrm{m}_{\text {sto }}$ is the particular value of $\mathrm{m}$ in stoichiometric conditions. For kerosene F.34 we have obtained 
$\mathrm{m}_{\text {sto }}=77.79$ moles of air for one mole of kerosene. The experimental determination of the partial pressure $\mathrm{P}_{\mathrm{ker}}$ of the kerosene has been carried out in the laboratory by Sochet et al. [7,8]. It has been shown that the partial pressure could be written for the studied range of temperatures:

$\mathrm{P}_{\mathrm{ker}}(\mathrm{Pa})=\exp \left[18.5-3506.6 / \mathrm{T}_{\mathrm{o}}\right]$

where $T_{\mathrm{o}}$ is expressed in Kelvin.

It can be noticed that the partial pressure of the kerosene only depends on the initial temperature. In the same way, the equivalence ratio $\varphi$ of the mixture is completely determined by the initial conditions. Different equivalence conditions are further considered, based on several values of the initial temperature and hence on different values of $\mathrm{m}$ in the chemical reaction.

The kerosene concentration may be deduced [10]:

$\mathrm{C}_{\mathrm{o}}=\frac{\mathrm{P}_{\mathrm{ker}}}{\mathrm{RT}_{\mathrm{o}}}$

where $\mathrm{R}$ is the ideal gas constant.

Hence:

$\mathrm{C}_{\mathrm{o}}=\frac{1}{\mathrm{RT}_{\mathrm{o}}} \exp \left[18.5-3506.6 / \mathrm{T}_{\mathrm{o}}\right]$

The kerosene concentration is independent of the initial pressure in the vessel.

The coefficients of the global equation remain positive only for well-defined equivalence ratios. Then, the chemical reaction has to be adapted [10] to fix values of the chemical equation coefficients $\alpha, \beta, \mathrm{r}$ to take into account separately the particularities of rich and lean mixtures.

- $\quad$ kinetics of lean mixtures:

In this case there is no condensation. The reaction is considered without hydrogen molecules and without $\mathrm{CO}$. This last condition is equivalent for stoichiometric conditions to the absence of oxygen in excess and expresses the continuity of the chemical equation system.

Hence:

$\beta=0 \quad \alpha=x \quad r=m-\frac{y}{4}-x$

The positive character of the equation coefficients leads to $\varphi \leq 1$.

- kinetics of rich mixtures:

The description of kerosene explosions in rich mixtures and for high temperatures requires the introduction of condensation phenomena and the formation of solid carbon $[7,8]$.

In order to keep a continuous evolution of the physical phenomena, the formation of solid carbon will be also taken into consideration for slightly or fairly rich mixtures.

In a rich mixture there is no oxygen in excess.

- If the reaction is supposed without $\mathrm{CO}$ and without hydrogen molecules we have then:

$\mathrm{r}=0 \quad \alpha=\mathrm{m}-\frac{\mathrm{y}}{4} \quad \beta=\mathrm{x}-\alpha$ 
The corresponding range of validity is specific of fairly rich mixtures that are essentially studied in this paper and such as: $1 \leq \varphi \leq 3.1$.

- If the reaction is supposed without $\mathrm{CO}$ and without $\mathrm{CO}_{2}$, we have then:

$$
\mathrm{r}=0 \quad \alpha=0 \quad \beta=\mathrm{x}
$$

The corresponding range of validity is: $\varphi \geq 3.1$.

The different cases envisaged allow a large application of the chemical kinetics from lean mixtures to rich mixtures.

The rate $\omega$ of the chemical reaction in the previous one-step reaction model is expressed in the form of a simple law [11] which does not take into account dissociation phenomena, but allows to have convenient calculation times. It writes:

$\omega=\mathrm{AP}^{0.3} \mathrm{~T}\left[\mathrm{C}_{\mathrm{x}} \mathrm{H}_{\mathrm{y}}\right]^{\alpha}\left[\mathrm{O}_{2}\right]^{\beta} \exp \left(-\mathrm{E}_{\mathrm{a}} / \mathrm{RT}\right)$

where:

$\mathrm{P}$ is the pressure given in atm.

$\mathrm{T}$ is the temperature in degrees $\mathrm{K}$.

Concentrations $\left[\mathrm{C}_{\mathrm{x}} \mathrm{H}_{\mathrm{y}}\right]$ or $\left[\mathrm{O}_{2}\right]$ are expressed in $\mathrm{mol} / \mathrm{cm}^{3}$.

The reaction rate $\omega$ is then expressed in $\mathrm{mol} / \mathrm{cm}^{3} \mathrm{~s}$.

The other constants in the formula (frequency factor, exponents and activation energy) have been chosen from data available in the literature [11]. However, it can be noticed that the expression given by Najjar at al. is not specific of kerosene F.34 and the frequency factor has been adapted to fit experimental results. With the previous units we have:

$\mathrm{A}=2.10^{3} \quad \alpha=0.5 \quad \beta=1 \quad$ and $\quad \mathrm{E}_{\mathrm{a}} / \mathrm{R}=13600$

The initial characteristics of the gaseous mixture are known (pressure $\mathrm{P}_{\mathrm{o}}$, temperature $\mathrm{T}_{\mathrm{o}}$ ), or may be calculated like the concentrations, as a function of the vessel volume for instance in the stoichiometric conditions. At the stoichiometry the volumetric percentage of kerosene is $\mathrm{p}_{\text {sto }}=1.3 \%$

The evolution of the thermodynamic variables (pressure, temperature, concentrations...) ensues from the resolution of a system of partial differential equations (PDE) taking into account heat and mass transport phenomena and the flow in the vessel.

* Mass continuity equation:

$\vec{\nabla} \bullet(\rho \vec{V})+\frac{\partial \rho}{\partial \mathrm{t}}=0$

where:

$\rho$ is the fluid density.

$\overrightarrow{\mathrm{V}}(\mathrm{u}, \mathrm{v}, \mathrm{w})$ is the flow velocity in the gaseous mixture.

* Navier-Stokes equations:

They describe the motion of kerosene molecules in a gaseous mixture with the following expression in the assumption of a weakly compressible fluid without body forces: 
$\rho \frac{\partial \overrightarrow{\mathrm{V}}}{\partial \mathrm{t}}+\rho \overrightarrow{\mathrm{V}} \bullet \vec{\nabla} \overrightarrow{\mathrm{V}}=\vec{\nabla} \bullet\left[-\mathrm{PI}+\eta\left(\vec{\nabla} \overrightarrow{\mathrm{V}}+(\vec{\nabla} \overrightarrow{\mathrm{V}})^{\mathrm{T}}\right)-\frac{2}{3} \eta(\vec{\nabla} \bullet \overrightarrow{\mathrm{V}}) \mathrm{I}\right]$

where:

$\mathrm{P}$ is the pressure in the ambient medium.

$\mathrm{I}$ is the $3 \times 3$ identity matrix.

The dynamic viscosity $\eta$ depends on the temperature according to the expression:

$\eta($ Pa.s $)=1.156 .10^{-6} \exp (1285.15 / \mathrm{T})$

* Thermal transport equation:

The evolution of the temperature in the mixture is given by:

$\rho \mathrm{C}_{\mathrm{p}}\left(\frac{\partial \mathrm{T}}{\partial \mathrm{t}}+\overrightarrow{\mathrm{V}} \bullet \vec{\nabla} \mathrm{T}\right)+\frac{\mathrm{T}}{\rho} \frac{\partial \rho}{\partial \mathrm{T}} \frac{\partial \mathrm{P}}{\partial \mathrm{t}}=\mathrm{q}+\vec{\nabla} \bullet(\lambda \vec{\nabla} \mathrm{T})$

In the assumption of an ideal gas the equation may be reduced to:

$\rho \mathrm{C}_{\mathrm{p}}\left(\frac{\partial \mathrm{T}}{\partial \mathrm{t}}+\overrightarrow{\mathrm{V}} \bullet \vec{\nabla} \mathrm{T}\right)-\frac{\partial \mathrm{P}}{\partial \mathrm{t}}=\mathrm{q}+\vec{\nabla} \bullet(\lambda \vec{\nabla} \mathrm{T})$

The thermal conductivity $\lambda$ also depends on the temperature and can be expressed by:

$\lambda(\mathrm{W} / \mathrm{mK})=-4.82 .10^{-9} \mathrm{~T}^{2}+5.81 .10^{-5} \mathrm{~T}+7.53 .10^{-3}$

The values of the specific heat capacities $C_{p}$ are deduced from expressions obtained by the Gaseq code (2005) for $\mathrm{n}$-decane in the form of a polynomial development between 300 and $5000 \mathrm{~K}$.

Precisely, the calculation of the global $C_{p}$ for the mixture depends on each species present in the vessel. A constant chemical composition is assumed for burnt and unburnt gases, so that:

$\mathrm{C}_{\mathrm{p}}=(1-\xi) \mathrm{C}_{\mathrm{pug}}+\xi \mathrm{C}_{\mathrm{pbg}}$

The reaction rate $\xi \in[0,1]$ is defined by: $\quad \xi=1-\frac{\mathrm{x}_{\mathrm{c}}}{\mathrm{x}_{\mathrm{co}}}$

where $\mathrm{x}_{\mathrm{c}}$ is the molar fraction of the fuel calculated at each step of the reaction and $\mathrm{x}_{\mathrm{co}}$ its initial value.

The specific heat capacity of unburnt gases $\mathrm{C}_{\mathrm{pug}}(\mathrm{J} / \mathrm{mol} . \mathrm{K})$ is then estimated (18) by:

$\mathrm{C}_{\text {pug }}=8.22471424858110^{-22} \mathrm{~T}^{6}-1.23218992239610^{-17} \mathrm{~T}^{5}-2.45225706392410^{-14} \mathrm{~T}^{4}$

$+1.20515555010810^{-9} \mathrm{~T}^{3}-7.46693649448110^{-6} \mathrm{~T}^{2}+1.97698937111010^{-2} \mathrm{~T}+26.2828936976$

In the same way, we obtain for the specific heat capacity of burnt gases $C_{p b g}$ (19):

$\mathrm{C}_{\mathrm{pbg}}=4.48932592382110^{-21} \mathrm{~T}^{6}-9.14573436729110^{-17} \mathrm{~T}^{5}+6.63239343923910^{-13} \mathrm{~T}^{4}$

$-1.86327398197910^{-9} \mathrm{~T}^{3}-7.68581564323610^{-8} \mathrm{~T}^{2}+1.05567542424210^{-2} \mathrm{~T}+27.34636843459$ 
These polynomial expressions result from Gaseq v0.79 computations [12], for a stoichiometric ndecane/air mixture (adiabatic combustion). The n-decane data are extracted from works by Dagaut and Cathonnet [13].

Finally, the heat production rate $\mathrm{q}\left(\mathrm{W} / \mathrm{m}^{3}\right)$ is connected to the reaction rate $\omega$ by the formula:

$\mathrm{q}=\omega \mathrm{M}_{\mathrm{p}} \mathrm{Q}+\mathrm{q}_{\mathrm{ign}}$

where:

$\mathrm{M}_{\mathrm{p}}$ is the molar mass of kerosene.

$\mathrm{Q}$ is the heat of combustion of kerosene such as $\mathrm{Q}=4.33 .10^{7} \mathrm{~J} / \mathrm{kg}$.

The ignition is obtained by the supply of a localized initial heat production rate $\mathrm{q}_{\text {ign }}$ described by a gaussian space-time distribution.

The spatial part of $\mathrm{q}_{\mathrm{ign}}$ is a function such as:

$f(x, y)=q_{\text {ign }}^{o} \exp \left[-\left(\frac{x-x_{p}}{\sigma}\right)^{2}-\left(\frac{y-y_{p}}{\sigma}\right)^{2}\right]$

where:

$\mathrm{q}_{\mathrm{ign}}^{\mathrm{o}}$ is the heat production rate $\left(\mathrm{W} / \mathrm{m}^{3}\right)$ initially brought to the mixture.

$\mathrm{x}_{\mathrm{p}}$ and $\mathrm{y}_{\mathrm{p}}$ are the coordinates of the hot point.

$\sigma$ is the standard deviation of the Gauss function.

In the same way, the part depending on time has a similar shape centred around a time $t_{0}$.

The characteristics of the ignition zone have been chosen such as: $t_{0}=5 \mathrm{~ms}$ and $\sigma=5 \mathrm{~mm}$.

The area of the time peak has been normalized to unity.

The area of the spatial part is $\pi \sigma^{2} \mathrm{q}_{\text {ign }}^{o}$

The total energy $E_{\text {ign }}$ provided to the ignition is therefore: $E_{\text {ign }}=\pi \sigma^{2} q_{\text {ign }}^{o}$

* Fuel transport equation:

The diffusion of the kerosene molecules in the gaseous mixture is taken into account in a conservative form.

Setting also $\mathrm{C}=\left[\mathrm{C}_{\mathrm{x}} \mathrm{H}_{\mathrm{y}}\right]$ the fuel concentration, we have then:

$\frac{\partial \mathrm{C}}{\partial \mathrm{t}}+\vec{\nabla} \bullet(\mathrm{C} \overrightarrow{\mathrm{V}}-\mathrm{D} \vec{\nabla} \mathrm{C})=-\omega$

where the diffusion coefficient $\mathrm{D}$ is given by : $\mathrm{D}\left(\mathrm{m}^{2} / \mathrm{s}\right)=3.95 .10^{-4} \cdot \frac{\mathrm{T}^{3 / 2}}{\mathrm{P}}$

The physico-chemical data used in the previous expressions such as the thermal conductivity $\lambda$, the dynamic viscosity $\eta$ or the specific heat capacity $C_{p}$ are generally depending on the temperature and have been determined either from works performed in the laboratory or from data available in the literature [12] and sometimes with analogies with n-decane [13]. Finally the closure of the system of PDEs is obtained by linking thermodynamic variables with the perfect gas law. Hence:

$\mathrm{P}=\rho \mathrm{rT}$ 
The resolution of the previous system allows then to determine the time and space evolutions of all thermodynamic data and of all concentrations.

\section{Numerical results in a single compartment vessel}

We intend now to study the behaviour of the previous model applied to kerosene vapors $[6,14]$ in a simple configuration.

Afterwards, the model will be tested on more complex systems with a particular geometry defining several compartments in order to study the evolution of the thermodynamic variables.

Figure 1 is composed of the evolutions of the pressure, the temperature and the velocity field in a single compartment vessel after a reaction time $t=4 \mathrm{~s}$. Due to the symmetry of the studied geometry, the tank may be likened to a rectangular surface with dimensions $20 \mathrm{~cm} \mathrm{x} 100 \mathrm{~cm}$ for 2D applications.

The ignition may be taken into account in the calculation through of a heat production rate such as $\mathrm{q}_{\mathrm{ign}}^{\mathrm{o}}=2.10^{6} \mathrm{~W} / \mathrm{m}^{3}$ localized at a point with the following coordinates $\left(\mathrm{x}_{\mathrm{p}}=10 \mathrm{~cm} ; \mathrm{y}_{\mathrm{p}}=10 \mathrm{~cm}\right)$.

The studied mixture is stoichiometric with thermodynamic conditions such as $\mathrm{P}_{\mathrm{o}}=150 \mathrm{kPa}$ and $\mathrm{T}_{\mathrm{o}}=320 \mathrm{~K}$. The calculations are done for Navier-Stokes equations with an approach of a weakly compressible fluid flow. The velocity field shows the trajectory followed by the gaseous molecules in the tank with a quicker circular evolution around the ignition zone.

Figure 1 also shows a distribution of temperatures in the different areas of the tank, around $2400 \mathrm{~K}$ for the blue-tinted areas and up to $3400 \mathrm{~K}$ for the red zones close to the hot point where the temperature due to the energy supply is higher.

The lowest temperatures, far from the ignition are consistent with those obtained for comparable gaseous mixtures [15]. The layout of the colours also shows the progression of the flow.

Finally, the pressure field is practically uniform [16,17] around $\mathrm{P}_{\max }=1.42 \mathrm{MPa}$. This kind of configuration may be obtained at different times of the reaction process and let appear no overpressure in the vessel which is coherent with results known in single compartments with weak volumes [18].

As an example, figure 2 represents the propagation of the flame front inside the vessel with the layout of the velocities at the beginning of the reaction for $t=100$ and $400 \mathrm{~ms}$. The results obtained are consistent with the expected phenomenology. Similar evolutions in the form of coloured areas may be visualized to study the evolution of pressure or concentration gradients.

The model also allows to study the influence of the equivalence ratio and to see the evolution of the thermodynamic conditions in rich and lean mixtures [18]. Due to its practically constant behaviour, the pressure appears as a very interesting parameter to validate the model.
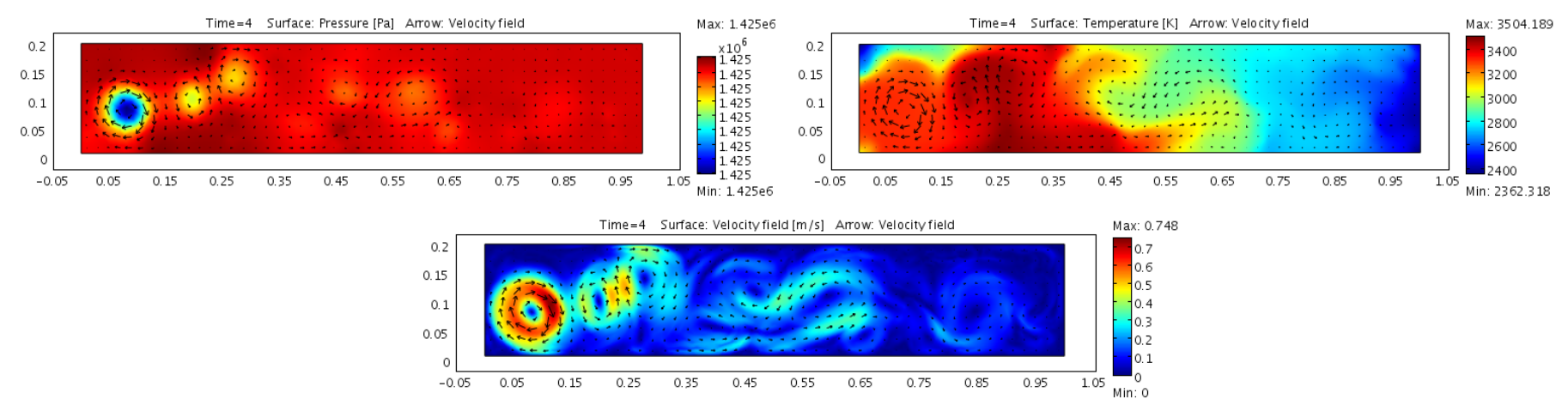

Fig. 1 Pressure, temperature and velocity field at the stoichiometry $(150 \mathrm{kPa} ; 320 \mathrm{~K})$ 

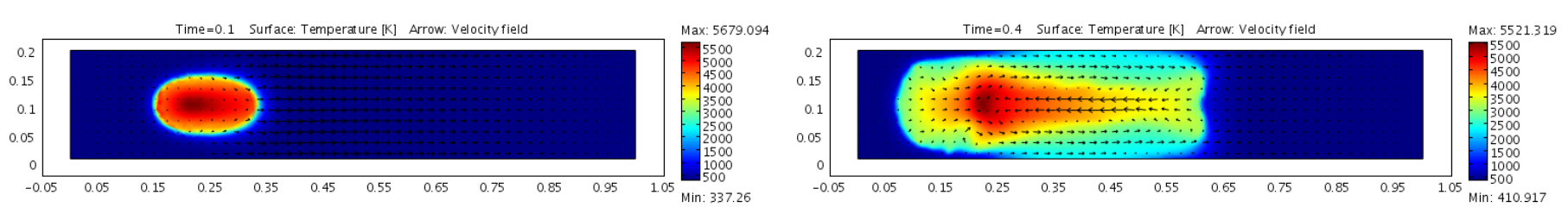

Fig. 2 Propagation of the flame front for $\mathrm{t}=100$ and $400 \mathrm{~ms}$ at the stoichiometry

Figure 3 gives the time evolution of the absolute pressure for mixtures with different equivalence ratios corresponding to initial temperatures comprised between 325 and $310 \mathrm{~K}$ and an initial pressure $\mathrm{P}_{\mathrm{o}}=150 \mathrm{kPa}$.

For a chosen equivalence ratio, all the points in the geometry provide a homogeneous behaviour of the time evolution of the pressure linked to low Mach numbers [16].
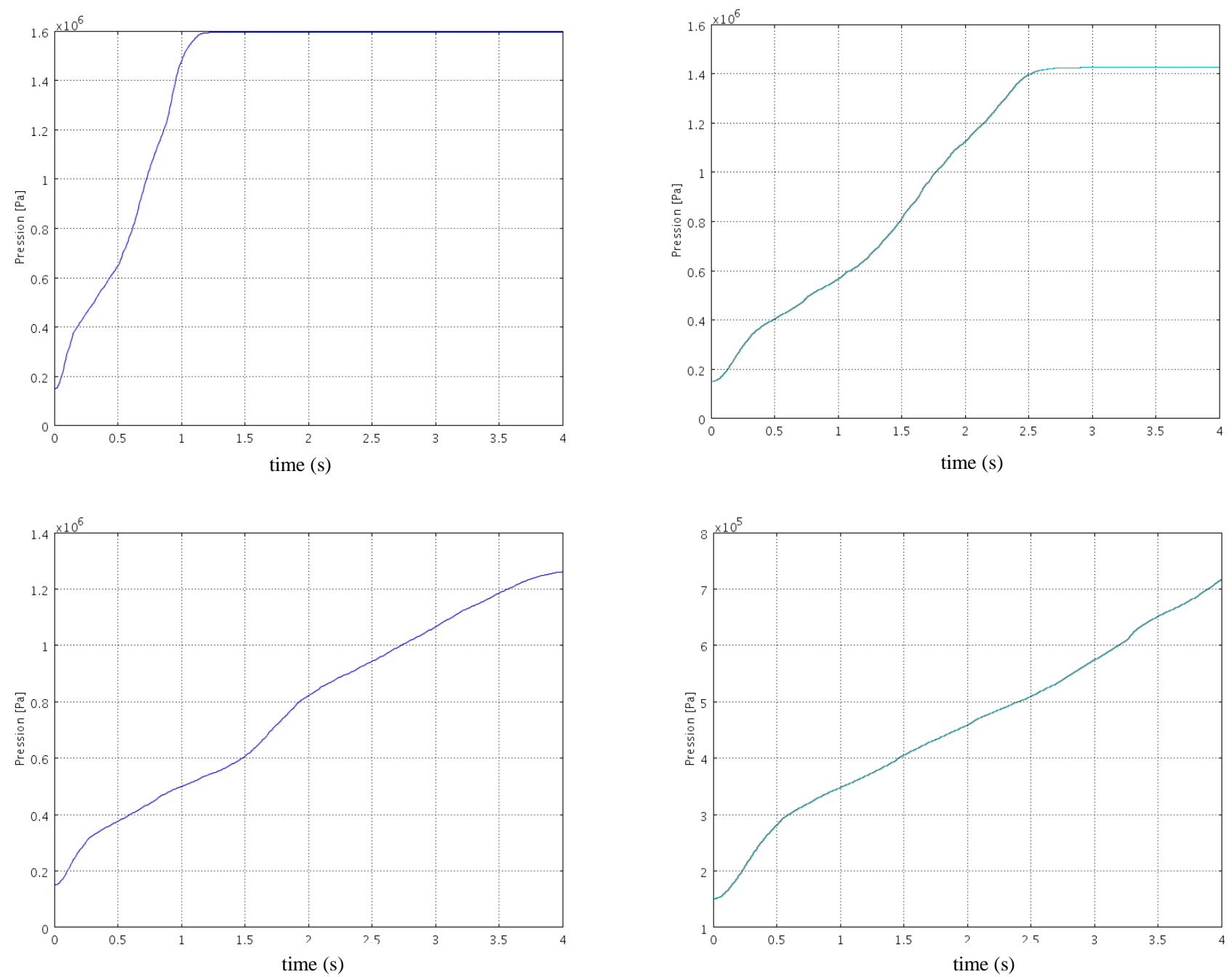

Fig. 3 Pressure vs time for different equivalence ratios $(\varphi=1.2 ; 1 ; 0.8 ; 0.7)$

If the ignition occurs in a rich mixture $(\varphi=1.2)$, the maximum pressure obtained is $\mathrm{P}_{\max }=1.6 \mathrm{MPa}$ for rise times of the order of $1 \mathrm{~s}$. At the stoichiometry, the maximum pressure is $\mathrm{P}_{\max }=1.4 \mathrm{MPa}$ for rise times near $2.5 \mathrm{~s}$.

In lean mixtures, the maximum pressure decreases from $\mathrm{P}_{\max }=1.22 \mathrm{MPa}$ for $\varphi=0.8$ to $1 \mathrm{MPa}$ for $\varphi=0.7$ and the rise times become notably longer over $4 \mathrm{~s}$. In very lean mixtures, the model reproduces the lower flammability limit phenomenon and there is no reaction observed. 
A classical stabilisation of the maximum pressure reached is observed for very long times [16]. The increase of the temperature in a lean mixture leads to a progressive increase of the maximum pressure and to a decrease of the rise times. The system gets nearer the stoichiometric conditions. It can also be noticed that when the initial pressure $\mathrm{P}_{\mathrm{o}}$ is higher, the stoichiometric conditions correspond to a higher maximum pressure with slightly quicker rise times [16].

The increase of the temperature beyond the stoichiometric conditions leads to an increase of the maximum pressure reached and to a stabilisation of the rise times for very rich mixtures. For the pressure, conditions near the stoichiometry still exist in relatively rich mixtures with a typical evolution of gaseous mixtures or dust suspensions [16].

Furthermore, our results (calc 1.) have been compared with the Gaseq code [12] which is a very simple 0D model (adiabatic combustion at constant volume and no dissociation) giving the maximum pressures and are presented in figure 4.

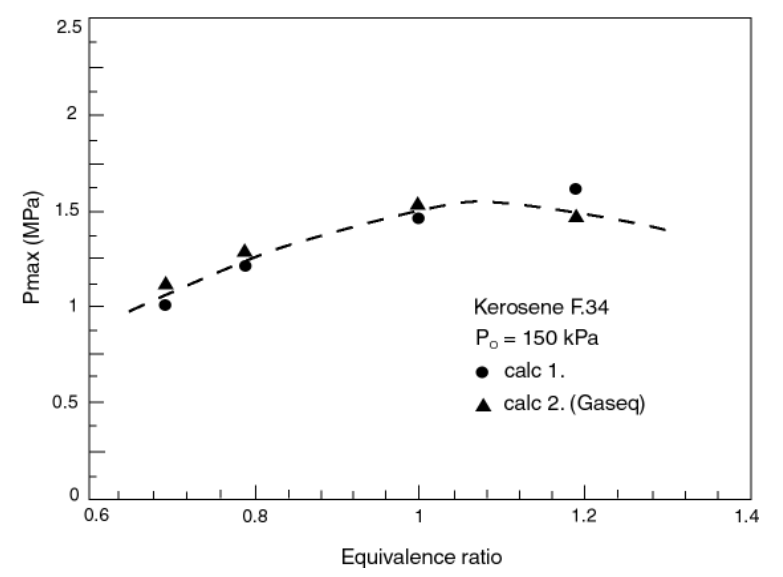

Fig. 4 Calculated maximum pressures vs the equivalence ratio $(\varphi=0.7 ; 0.8 ; 1 ; 1.2)$

A very good agreement is obtained for the investigated equivalence ratios with a classical behaviour particularly around the stoichiometry. Finally, all the results presented in a single compartment show a relatively consistent adaptation of the model to the description of the explosions of kerosene vapors $[16,15]$.

\section{Numerical results within a $2 \times 2$ partitioned vessel}

\subsection{GEOMETRY, MESH, INITIAL AND BOUNDARY CONDITIONS}

Numerical results are first described for a closed vessel divided into four compartments $(2 \times 2)$. Their size is $920 \times 200 \mathrm{~mm}^{2}$ each. The walls separating the compartments feature two horizontal and a vertical orifices, so that the global area blockage is about $50 \%$ for each wall. The openings display rounded shapes. The wall thickness is $20 \mathrm{~mm}$.

The corresponding unstructured mesh is shown in figure 5. The cell size is mainly constant $(\Delta \mathrm{x}=1 \mathrm{~cm})$, with refinements very near the orifices and also within the ignition zone.

As the flame thickness is typically $\sim 0.1 \mathrm{~mm}$ for hydrocarbons in standard conditions, it is important to determine a correct mesh for such large geometries. For this reason, the mesh size has been chosen sufficiently thin, so that the duration of the combustion obtained in a single compartment is such as: one meter of the mixture is burned in $3 \mathrm{~s}$, which is consistent with the laminar burning velocity of stoichiometric hydrocarbon-air mixtures (typically $30-40 \mathrm{~cm} / \mathrm{s}$ ). 


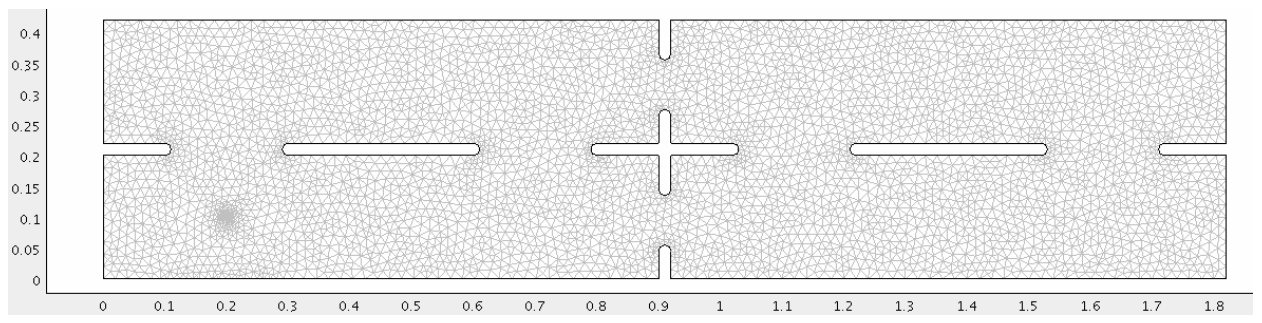

Fig. 5 Mesh and geometry for a 2x2 compartments tank.

The walls are supposed adiabatic with non-slipping conditions. Initial temperature and pressure are $\mathrm{T}_{\mathrm{o}}=320.5 \mathrm{~K}$ and $\mathrm{P}_{\mathrm{o}}=1.5 \mathrm{bar}$, so that the kerosene-air mixture is stoichiometric. This corresponds to hot conditions at the sea level. It is worth noticing that this value of the equivalence ratio is retained because the mechanical effects of combustion are nearly maximized (final pressure or rate of pressure rise).

The radius of the ignition zone is such as $\sigma=5 \mathrm{~mm}$ (area $\mathrm{a}=0.78 \mathrm{~cm}^{2}$ ). The duration and amplitude parameters are respectively equal to $\Delta \mathrm{t}=5 \mathrm{~ms}$ and $\mathrm{q}_{\mathrm{ign}}^{\mathrm{o}}=2 \mathrm{MW} / \mathrm{m}^{2}$. The ignition energy is then $157 \mathrm{~J}$. Ignition occurs within the bottom-left compartment $\left(\mathrm{x}_{\mathrm{p}}=20 \mathrm{~cm}, \mathrm{y}_{\mathrm{p}}=10 \mathrm{~cm}\right)$.

\subsection{PHENOMENOLOGICAL DESCRIPTION OF THE COMBUSTION PROCESS}

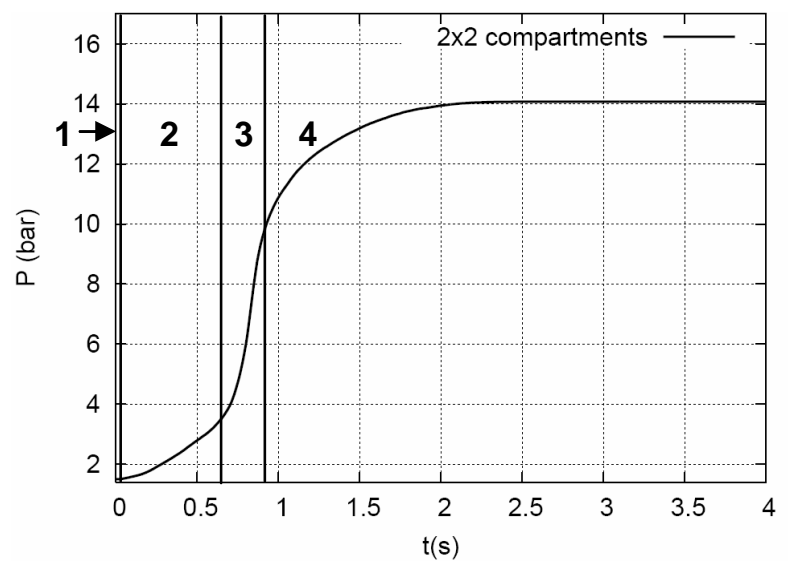

Fig. 6 Pressure evolution for a $2 \times 2$ compartments vessel.

In this part, the emphasis is mainly put on mechanical effects of combustion, and the pressure evolution is reported in figure 6 . One can divide the reactive process into four steps: the first one corresponds to ignition $(0<\mathrm{t}<0.01 \mathrm{~s})$, which proceeds at nearly constant pressure. Then pressure increases at a limited rate $(0.01<\mathrm{t}<0.65 \mathrm{~s})$. The highest rate of pressure rise is reached during the third step, up to $40 \mathrm{bar} / \mathrm{s}(0.65<\mathrm{t}<0.9 \mathrm{~s})$. During the last step, the global combustion process slows down and pressure stabilizes around $\mathrm{P}=14$ bar. As previously, it can be noticed that the pressure field remains practically uniform during the whole process.

These different steps result of the local features of the combustion process, as shown by the temperature fields in figure 7. Please note that for more clarity, the time separating two consecutive fields varies. As moderate energy level is provided for ignition, the pressure rise is negligible during this first step. Thereafter, the flame propagates nearly spherically around the ignition kernel and reaches the upper compartment. Its shape remains regular during the most part of the second step. The expansion of the burned gases moves fresh gases into the right part of the vessel, which forms a horizontal unsteady jet flow near the vertical orifices. The maximum velocity with the jet of fresh gases reaches up to $6 \mathrm{~m} / \mathrm{s}(\mathrm{t}=0.3 \mathrm{~s})$. Then the jet flow presents instabilities, and several vortex structures appear. At this time, the flame reaches the right compartments $(t=0.5 \mathrm{~s})$ as it can be seen in figure 8 . After $t=0.6 \mathrm{~s}$, the shape of the flame becomes less regular, as a result of the flow 
previously generated in the right part of the vessel. Consequently, the total flame length (2D domain) is increased, leading to a higher global combustion rate. This is probably the main phenomenon at the origin of the higher slope shown in figure 6 during the third step. During the last step of the combustion, the shape of the flame front recovers a regular shape as the fresh gas surface is reduced. An apparent slower propagation of the flame front is observed. It reflects the negligible expansion effects in the fresh mixture during the final part of the combustion. It can be noticed that a reverse flow is produced by the orifices located on the vertical walls, as a result of the expansion of the burnt gases in the right part of the vessel $\left(\mathrm{V}_{\max }=7-8 \mathrm{~m} / \mathrm{s}, \mathrm{t}=0.8 \mathrm{~s}\right)$. Then, the jet flow quickly changes into a large scale vortex pattern, observed until the end of the combustion.

It is worth noting that despite the simplicity of the description, the acceleration of combustion in presence of orifices is reproduced [19].
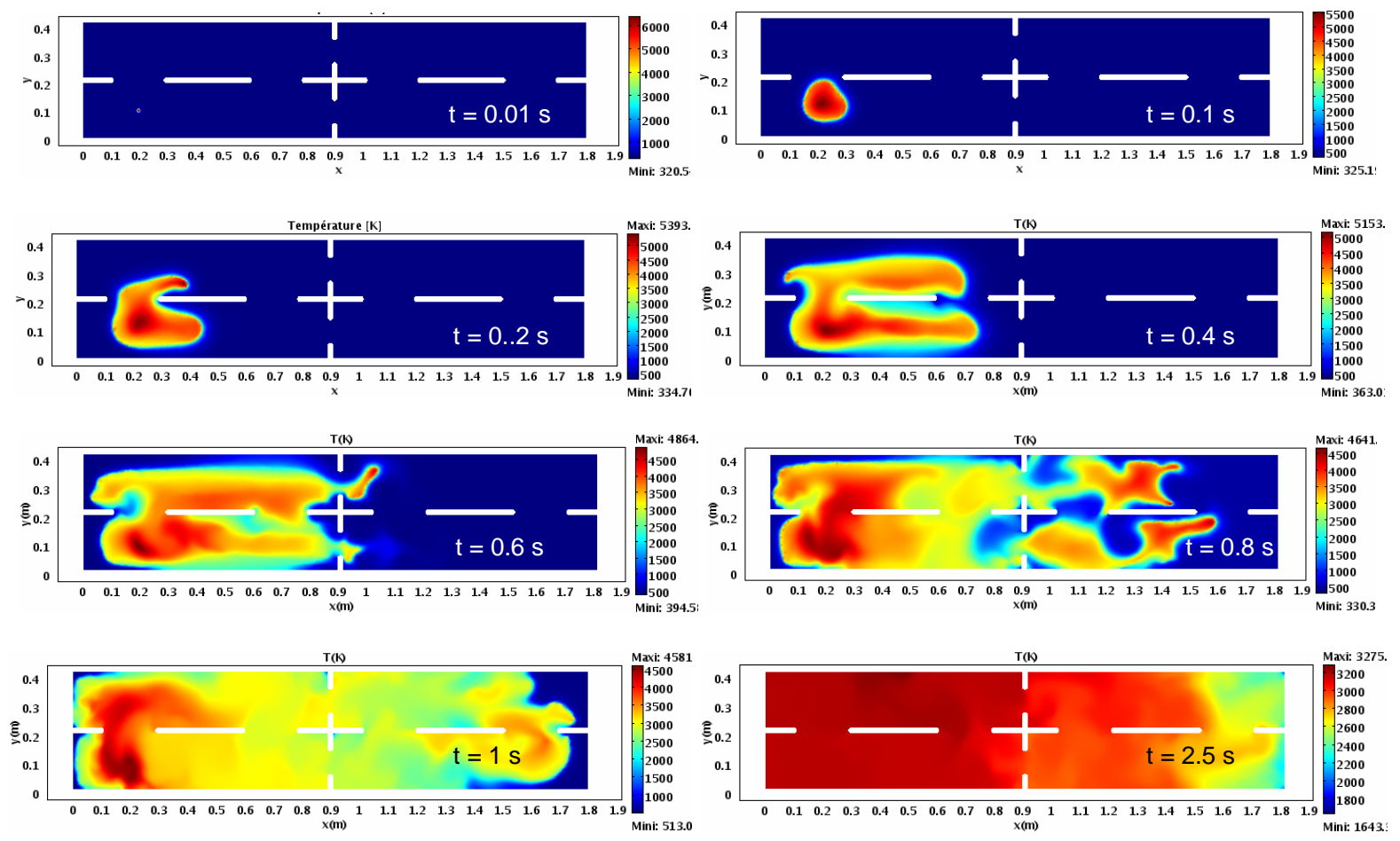

Fig. 7 Temperature fields at different times.
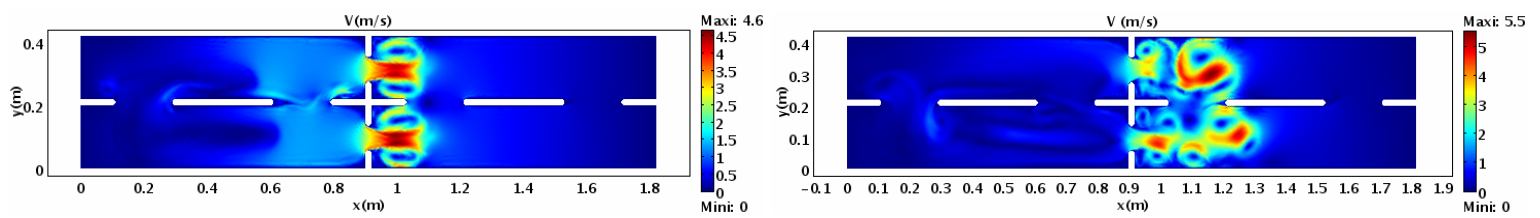

Fig. 8 Velocity fields (magnitude) at $\mathrm{t}=0.3 \mathrm{~s}$ (left) and $\mathrm{t}=0.5 \mathrm{~s}$ (right)

\subsection{INFLUENCE OF THE IGNITION LOCATION}

Two positions are considered: the first one corresponds to the previous case $\left(x_{p}=20 \mathrm{~cm}\right.$, $\mathrm{y}_{\mathrm{p}}=10 \mathrm{~cm}$ ) in the bottom-left compartment. The second one is located in the same compartment, but at the vicinity of the right orifice $\left(x_{p}=85 \mathrm{~cm}, y_{p}=10 \mathrm{~cm}\right)$. Other ignition parameters are kept unchanged. 


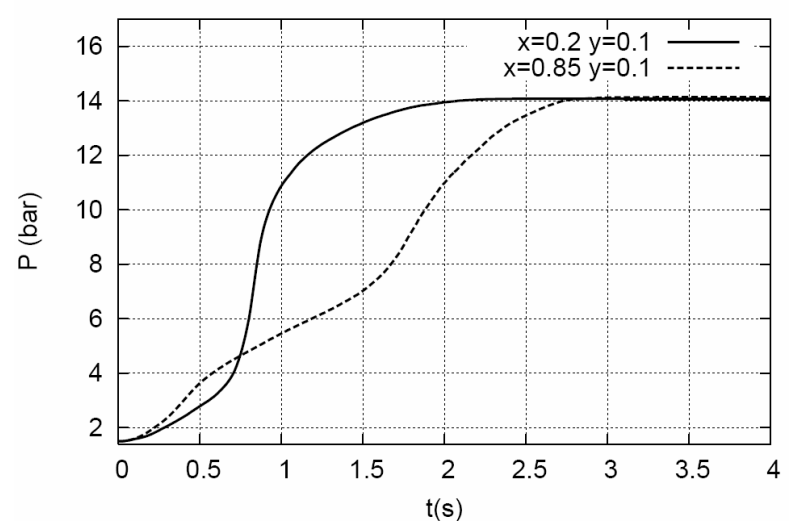

Fig. 9 Pressure evolutions for two different ignition locations

Corresponding pressure histories are reported in figure 9. For the first position, an increase of the rate of pressure rise is reported when the flame crosses the vertical orifices (up to $40 \mathrm{bar} / \mathrm{s}$ ). When ignition occurs near the middle orifice, the pressure rise is slower (between 4 and $10 \mathrm{bar} / \mathrm{s}$ ). The acceleration effect due to the orifice is very moderated when ignition occurs in its vicinity. This is the reason why such pressure evolution presents some similarities with the case of a single compartment.

The strong influence of the ignition location must be underlined. It may be explained as follows: when ignition occurs near the orifice, the volume of the burnt gases is weak when the flame approaches the latter. Therefore moderate velocities are reached in the jet of fresh gases (up to 1.5 $\mathrm{m} / \mathrm{s}$ ). Thus, the flame is slightly perturbed by the residual flow after crossing the orifice. Therefore the combustion process is practically not accelerated in this case.

It can be noticed that the pressure rise remains moderated in the last times: as the flame mainly crosses horizontal orifices, which are the largest ones, there is no further acceleration.

\subsection{INFLUENCE OF THE SIZE OF THE IGNITION ZONE}

Two categories of fragments are considered to represent the effects of anti-aircraft ammunition: the first one corresponds to small and numerous fragments. The second category represents some larger fragments. Consequently, two values of the ignition volume are retained for ignition areas: $0.78 \mathrm{~cm}^{3}$ and $5 \mathrm{~cm}^{3}$. Considering a $1 \mathrm{~cm}$ depth cylinder, they correspond to $\sigma=5$ and $12.6 \mathrm{~mm}$. Other ignition parameters remain constant such as $\mathrm{q}_{\mathrm{ign}}^{\mathrm{o}}=2 \mathrm{MW} / \mathrm{m}^{2}$ and $\Delta \mathrm{t}=5 \mathrm{~ms}$. The resulting ignition energies $E_{\text {ign }}$ equal $157 \mathrm{~J}$ and $1 \mathrm{~kJ}$. These values have been chosen to represent real space-time characteristics of a projectile impact on an aircraft.

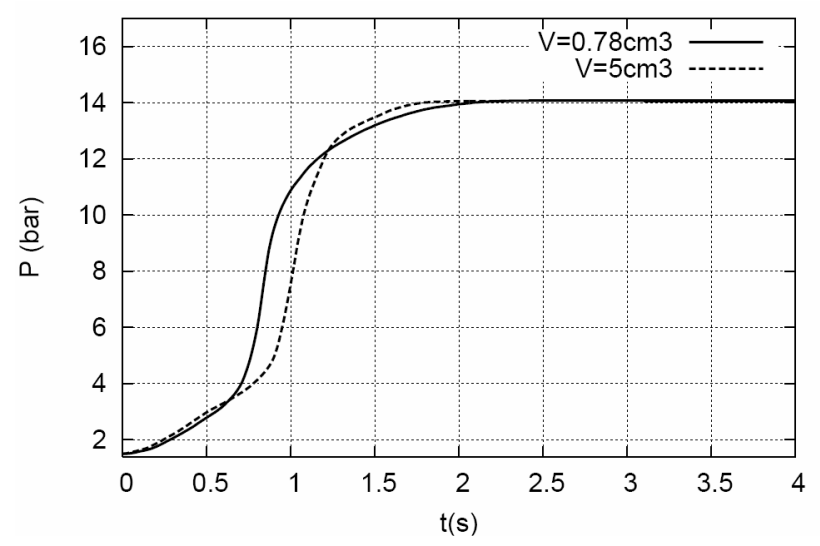

Fig. 10 Influence of the size of the ignition zone. 
The corresponding pressure evolutions are represented in figure 10. They are fairly similar. For the smaller ignition volume, the acceleration of the combustion occurs slightly earlier. The maximum rate of pressure rise reaches $40 \mathrm{bar} / \mathrm{s}\left(35 \mathrm{bar} / \mathrm{s}\right.$ for $\left.\mathrm{a}=5 \mathrm{~cm}^{2}\right)$. In conclusion, the pressure evolution is very slightly influenced by the ignition volume for the investigated values. It may however influence the development of the ignition for higher $\mathrm{q}_{\mathrm{ign}}^{\mathrm{o}}$ values.

\section{Numerical results within a complex multi-partitioned structure}

\subsection{ANALYSIS OF THE FLAME PROPAGATION PROCESS FOR 2X5 COMPARTMENTS}

Figure 11 shows the pressure evolution for a $2 \times 5$ configuration. It is similar to the $2 \times 2$ case, with the same steps in the reaction process and ignition parameters such as : $\mathrm{q}_{\mathrm{ign}}^{\mathrm{o}}=2 \mathrm{MW} / \mathrm{m}^{2}, \Delta \mathrm{t}=5 \mathrm{~ms}$, $\sigma=5 \mathrm{~mm}, \mathrm{x}_{\mathrm{p}}=20 \mathrm{~cm}, \mathrm{y}_{\mathrm{p}}=10 \mathrm{~cm}$. Temperature fields reported in figure 11 also show a similar development of the combustion : the flame shape remains regular during the two first steps, which is correlated to a similar low rate of pressure rise $0-5 \mathrm{bar} / \mathrm{s}$. Combustion also occurs first of all in the left compartments and jets of fresh gases are also successively formed by the vertical orifices.
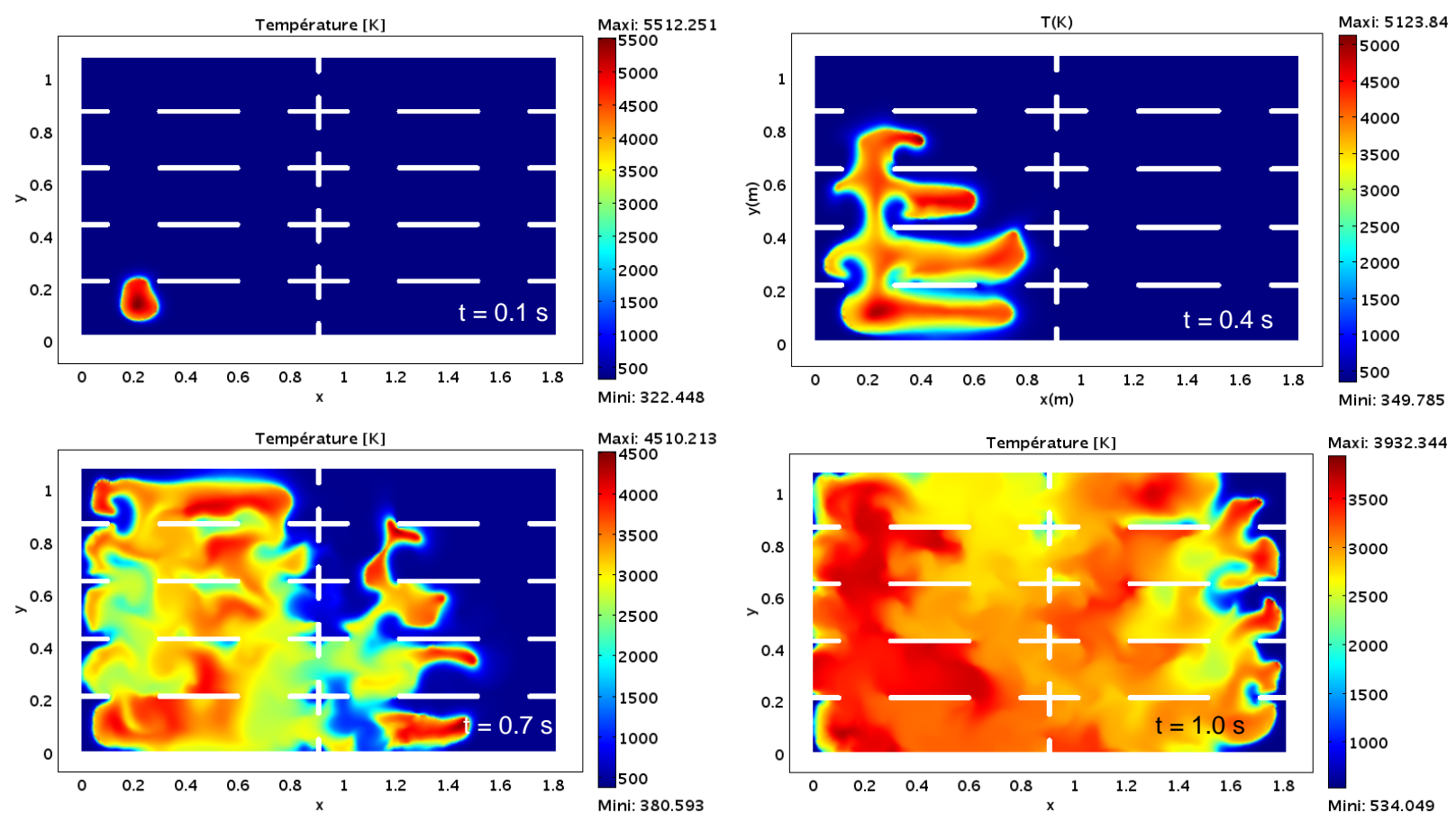

Fig. 11 Temperature fields at several times for a $2 \times 5$ compartment vessel

On the contrary of the $2 \times 2$ compartment case, jets of fresh mixture are also formed by horizontal orifices but with lower velocities $(1-3 \mathrm{~m} / \mathrm{s}$ instead of $3-7.5 \mathrm{~m} / \mathrm{s})$. Thereafter, the flame propagates in the right compartments. Its shape is perturbed by the residual flow induced by the orifices, which accelerates the combustion process (up to $38 \mathrm{bar} / \mathrm{s}$ ). The last step is qualitatively similar to the $2 \times 2$ case, with a proportionally longer flame which leads to an earlier stabilization of the pressure.

\subsection{COMPARISON OF THE MECHANICAL EFFECTS FOR DIFFERENT GEOMETRIES}

The retained approach is to modify the number of compartments. Each of them is chosen with the same size as previously. The following three configurations are considered: $1,2 \times 2,2 \times 5$. A $18 \mathrm{~cm}$ length is supposed for the depth of the chamber in our applications with the corresponding volumes 
32.4, 130 and 324 litres. The latter is the most representative of airplane fuel tanks. Ignition parameters are kept constant: $\mathrm{q}_{\mathrm{ign}}^{\mathrm{o}}=2 \mathrm{MW} / \mathrm{m}^{2}, \Delta \mathrm{t}=5 \mathrm{~ms}, \sigma=5 \mathrm{~mm}, \mathrm{x}_{\mathrm{p}}=20 \mathrm{~cm}, \mathrm{y}_{\mathrm{p}}=10 \mathrm{~cm}$.

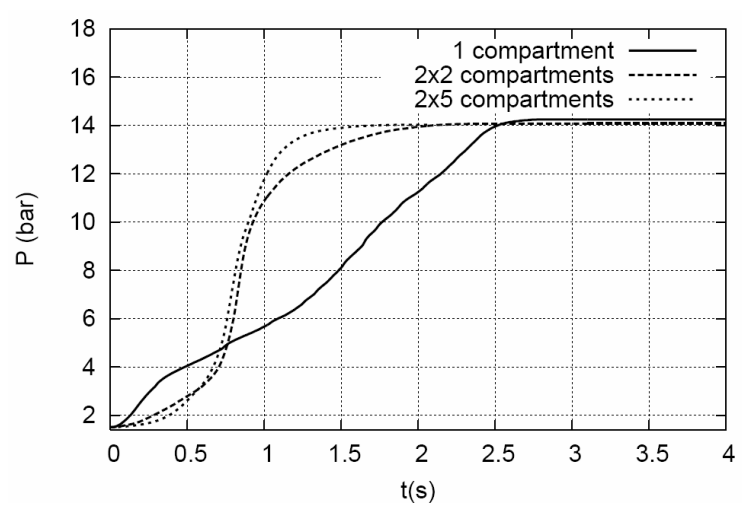

Fig. 12 Pressure evolutions for different geometries

Figure 12 reports pressure evolutions for the previous geometries. The highest rates of pressure rise are obtained for multi-partitioned vessels. This illustrates the acceleration of the combustion process in presence of obstacles and the formation of turbulence phenomena.

The $2 \times 2$ and $2 \times 5$ configurations are then compared to each other: the pressure histories are similar up to $0.9 \mathrm{~s}$. Thereafter, the higher rate of pressure rise is maintained for a longer duration in the $2 \times 5$ case, which shortens the combustion duration from $2 \mathrm{~s}$ to $1.5 \mathrm{~s}$. This effect was not expected, since for simplified 1D geometries, the combustion duration generally increases with the volume. In our case, the distance from the ignition point to the furthest wall is identical for both $2 \times 5$ and $2 \times 2$ cases (for a horizontal or a vertical path). This tends not to increase the combustion duration, if the flame celerity remains approximately constant. The combustion duration is even shorter for the $2 \times 5$ case, because the strong rate of pressure rise is maintained for a longer duration.

\section{Conclusion}

Explosions of kerosene vapors within aircraft tanks have been investigated by the means of a simple CFD code. Based on a 2D laminar approach and a one-step global reaction, a model has been developed to give the characteristics of the flame propagation inside simple or more complex structures.

In a single compartment the proposed development allows the study of varied initial conditions (pressure, temperature, volume), the influence of different parameters such as the equivalence ratio of the mixture, the duration, the size or the location of the ignition energy. The model predictions have been validated with experimental results and the Gaseq code with a very good agreement.

In partitioned vessels, the results obtained show an acceleration of the combustion process when the flame crosses the internal orifices. This is a well known behaviour in presence of obstacles; therefore the expected phenomenology is reproduced.

Particularly, investigations on a $2 \times 2$ compartment tank show that the rate of pressure rise remains moderate when ignition occurs near a vertical orifice. By contrast, the size of the ignition zone does not affect the propagation stage of the combustion.

The influence of the vessel geometry is also taken into account by modifying the number of compartments. Surprisingly, the largest vessel (2x5 compartments) exhibits a shorter combustion duration than the $2 \times 2$ configuration. This may be attributed to geometrical effects and to a longer step of strong pressure rise. This phenomenon illustrates the complexity of the addressed issue, and highlights the relevance of such a full CFD approach.

In conclusion, the model developed indicates correct trends for the effects due to the ignition and the flame propagation. In these conditions, the model proposed may be considered as a pertaining 
tool for further practical studies of vulnerability or risk estimation related to the explosion of kerosene vapors within aircraft tanks. More particularly, the influence of turbulence [19] which is a complex problem, the influence of heat transfers and external venting should be investigated in future works in order to improve the model predictions.

\section{Acknowledgments}

This work was financially supported by the Commissariat à l'Energie Atomique, Centre d'études de Gramat, under contract $N^{\circ} 200725009000510000$.

\section{Nomenclature}

$\begin{array}{ll}\alpha, \beta, \mathrm{m}, \mathrm{r} & \text { Chemical equation coefficients } \\ \mathrm{P}, \mathrm{P}_{\mathrm{o}}(\mathrm{Pa}) & \text { Pressure- Initial pressure } \\ \mathrm{T}, \mathrm{T}_{\mathrm{o}}(\mathrm{K}) & \text { Temperature- Initial temperature } \\ \mathrm{V}, \mathrm{V}_{\mathrm{o}}\left(\mathrm{m}^{3}\right) & \text { Volume- Vessel volume } \\ \mathrm{C}, \mathrm{C}_{\mathrm{o}}\left(\mathrm{mol} / \mathrm{m}^{3}\right) & \text { Kerosene concentration- Initial kerosene concentration } \\ \rho, \rho_{\mathrm{o}}\left(\mathrm{kg} / \mathrm{m}^{3}\right) & \text { Density- Initial density } \\ \mathrm{P}_{\mathrm{ker}}(\mathrm{Pa}) & \text { Partial pressure of kerosene } \\ \mathrm{M}_{\mathrm{p}}(\mathrm{kg} / \mathrm{mol}) & \text { Molar mass of kerosene. } \\ \mathrm{R}(\mathrm{J} / \mathrm{mol} \cdot \mathrm{K}) & \text { Ideal gas constant } \\ \varphi & \text { Equivalence ratio } \\ \omega\left(\mathrm{mol} / \mathrm{cm}{ }^{3} \mathrm{~s}\right) & \text { Reaction rate } \\ \mathrm{A}, \mathrm{e}, \mathrm{s} & \text { Frequency factor and exponents in the reaction rate } \\ \mathrm{E}_{\mathrm{a}}(\mathrm{J} / \mathrm{mol}) & \text { Activation energy } \\ \overrightarrow{\mathrm{V}}(\mathrm{m} / \mathrm{s}) & \text { Flow velocity } \\ \mathrm{u}, \mathrm{v}, \mathrm{W}(\mathrm{m} / \mathrm{s}) & \text { Components of the flow velocity } \\ \eta(\mathrm{Pa} . \mathrm{s}) & \text { Dynamic viscosity } \\ \lambda(\mathrm{W} / \mathrm{mK}) & \text { Thermal conductivity } \\ \mathrm{C}_{\mathrm{p}}(\mathrm{J} / \mathrm{mol} . \mathrm{K}) & \text { Specific heat capacity } \\ \mathrm{C}_{\mathrm{pbg}}, \mathrm{C}_{\mathrm{pug}}(\mathrm{J} / \mathrm{mol} . \mathrm{K}) & \text { Specific heat capacities of burnt/ unburnt gases } \\ \mathrm{q}\left(\mathrm{W} / \mathrm{m}^{3}\right) & \text { Heat production rate } \\ \mathrm{q}_{\mathrm{ign}}^{\mathrm{o}}\left(\mathrm{W} / \mathrm{m}^{3}\right) & \text { Heat production rate due to ignition } \\ \mathrm{E}_{\mathrm{ign}}(\mathrm{J}) & \text { Ignition energy } \\ \mathrm{Q}(\mathrm{J} / \mathrm{kg}) & \text { Heat of combustion of kerosene } \\ \mathrm{x}_{\mathrm{p}}, \mathrm{y}_{\mathrm{p}}(\mathrm{cm}), \mathrm{t}_{\mathrm{o}}(\mathrm{s}) & \text { Coordinates of the ignition point. } \\ \sigma(\mathrm{mm}) & \text { Standard deviation of the Gauss function } \\ \mathrm{t}(\mathrm{s}) & \text { Reaction time } \\ & \end{array}$

\section{References}

[1] Aggarwal S.K., Sirignano W.A., Comb. Flame 62, 69 (1985).

[2] Sirignano W.A., Continillo G., $22^{\text {nd }}$ International Symposium on Combustion, Seattle, 1988.

[3] Shepherd J.E., Krok J.C., Lee J.J., California Institute of Technology, Report FM97-5, 1997.

[4] Shepherd J.E., Krok J.C., Lee J.J., California Institute of Technology, Report FM97-9, 2000.

[5] Gascoin N., Gillard P., Energ. Fuels 24, 404 (2010). 
[6] Pascaud J.M., Brossard J., Valèze D., Eur. Phys. J. Appl. Phys. 9, 215 (2000).

[7] Sorin R., Bauer P. Desbordes D., Shock Waves 17, 363 (2008).

[8] Sochet I., Reboux A., Pascaud J.M., Brossard J., Rapport DGA nº 020087/CEG-DSI-DV, 1998.

[9] Pascaud J.M., Gillard P., J. Loss Prevent. Proc. 19, 271 (2006).

[10] Pascaud J.M., Brossard J., Lombard J.M., Eur. Phys. J. Appl. Phys. 7, 227 (1999).

[11] Najjar Y.S.H., Goodger E.M., Fuel 60, 980 (1981).

[12] Gaseq v0.79, "A chemical equilibrium program for windows", www.gaseq.co.uk,2005.

[13] Dagaut P., Cathonnet P., Prog. Energ. Combust. Sci. 32, 48 (2006).

[14] Sochet I., Pascaud J.M., Gillard P., 3rd International Symposium on Hazards, Prevention and Mitigation of Industrial Explosions, Tsukuba, 2000.

[15] Leuckel W., Nastoll W., Zarzolis N., 23rd International Symposium on Combustion, Orleans, 1990.

[16] Bartknecht W., Explosionen, Ablauf und Schutzmassnahmen, Springer-Verlag, Berlin, 1978.

[17] Bradley D., Mitcheson A., Comb. Flame 32, 221 (1978).

[18] Fairweather M., Hargrave G.K., Ibrahim S.S., Walker D.G., Comb. Flame 116, 504 (1998).

[19] Ciccarelli G., Dorofeev S., Prog. Energ. Combust. Sci. 34, 499 (2008). 